\title{
Color and opacity of composites protected with surface sealants and submitted to artificial accelerated aging
}

\author{
Fabiano Gamero Aguilar ${ }^{1}$ \\ Lucas da Fonseca Roberti Garcia' \\ Diogo Rodrigues Cruvinel ${ }^{1}$ \\ Ana Beatriz Silva Sousa ${ }^{1}$ \\ Fernanda de Carvalho Panzeri Pires-de-Souza ${ }^{1}$
}

\section{ABSTRACT}

Objectives: To evaluate the color similarity, stability and opacity of composites (TPH, Charisma, and Concept, shade A2) protected with surface sealants (Fortify Plus and Biscover) and cyanoacrylate (Super Bonder).

Methods: Forty specimens of each composite were made and separated into 4 groups (n=10) according to the surface protection: GI - without sealant; GII - cyanoacrylate; GIII - Fortify Plus; GIV - Biscover. Color and opacity readings were taken before and after Artificial Acelerated Aging (AAA) and the values obtained for color stability were submitted to statistical analysis by 2-way ANOVA and Bonferroni's test $(P<.05)$. The values acquired for color similarity were submitted to 1 -way ANOVA and Tukey's test $(P<.05)$. The specimen sufaces were compared before and after AAA using Scanning Electronic Microscopy (SEM).

Results: Studied composites did not present the same values for the coordinates $L^{*}$, $a^{*}$ and $b$ * before AAA, indicating that there was no color similarity among them. All composites presented color alteration after AAA with clinically unacceptable values. Protected groups presented lower opacity variation after AAA, in comparison with the control goup. SEM evaluation demonstrated that AAA increased the surface irregularities in all of the studied groups.

Conclusion: Surface sealants were not effective in maintaining composite color, but were able to maintain opacity. (Eur J Dent 2012;6:24-33)

Key words: Accelerated aging; color stability; composite; sealant.

1 Department of Dental Materials and Prosthodontics, Dental School of Ribeirão Preto, University of São Paulo. Av do Café, s/no - Monte Alegre - 14040-904 - Ribeirao Preto - SP - Brazil.

- Corresponding author: Dr. Fernanda de Carvalho Panzeri Pires-de-Souza Faculdade de Odontologia de Ribeirão Preto/USP, Departamento de Materiais Dentários e Prótese, Avenida do Café, s/n, Bairro Monte Alegre, 14040-904 Ribeirão Preto, SP, Brazil.

Tel: +55-16-3602-3973. Fax: +55-016-3633-0999. E-mail: ferpanzeri@forp.usp.br

\section{INTRODUCTION}

Color stability is crucial for the success of any type of esthetic restoration; in fact, color change is the major reason for replacing anterior restorations. ${ }^{1}$ Researchers agree that direct restorations using resin composites undergo color alteration over time..$^{2-5}$ The different types of composite discoloration are usually described in the literature as: 1) external discolorations due to plaque accu- 
mulation and staining substances; ${ }^{5,6}$ 2) surface or sub-surface alterations involving surface degradation and reaction of coloring agents with the resin composite layer (adsorption); 4,5 and 3) intrinsic discolorations due to physical-chemical reactions in the deep portions of the restoration..$^{7-10}$

The monomer degree of conversion also influences the chemical stability of composites. The presence of unreacted-carbon double bonds makes the material more susceptible to degradation, ${ }^{9}$ thus resulting in a reduction in color stability11 and possible release of formaldehyde and methacrylic acid. ${ }^{12}$ Moreover, an insufficient degree of conversion contributes to the absorption of coloring substances, inducing composite discoloration. 9,13,14 It has been observed that composites with high water sorption values were more easily stained by hydrophilic dyes present in drinks, such as wine, coffee and tea. ${ }^{15,16}$

Commercial composite resins are manufactured based on the Vitapan Classical shade guide (Vita-Zahnfabrik, Germany) ${ }^{17}$ with the aim of reducing the need to use different shade guides. However, changes in color and translucency after polymerization, polishing and thermal cycling, may vary by brand of composite resins and this information would be clinically useful. ${ }^{18}$

Surface sealants are used in combination with restorative composites to seal micro-porosity on restoration surfaces, thus increasing the marginal integrity and abrasion resistance, ${ }^{19,20}$ which could prevent or reduce the absorption of pigments from foods in the diet, and reduce staining, contributing to the color stability of composites. Another material commonly used in Dentistry is cyanoacrylate, ${ }^{21}$ which could be used as a surface sealant due to its biocompatibility, ${ }^{22}$ viscosity and easy handling in comparison with other materials. Moreover, cyanoacrylate does not need to be mixed with other components and it is chemically polymerized.

The aim of this study was to evaluate the color similarity of different brands of resin composites of the same color before Artificial Accelerated Aging (AAA); and the color stability and opacity variation of composites protected with surface sealants and cyanoacrylate, after being submitted to AAA. Two hypothesis were tested: the null hypothesis that there would be no significant difference in color coordinates between the same shade-designated resin composites from different brands, and that composites protected by surface sealants and cyanoacrylate would present less color alteration and opacity than the unprotected materials after AAA.

\section{MATERIALS AND METHODS}

In this study, three direct A2-shade resin composites, two surface sealants and a cyanoacrylatebased adhesive were used. Details of these materials are presented in Table 1.

Forty specimens were made of each composite using a cylindrical Teflon mold ( $14 \mathrm{~mm} \times 2 \mathrm{~mm}$ ), totaling 120 samples. The specimens were photoactivated by a halogen light device for 40 seconds (Ultralux Eletronic, Dabi Atlante, Ribeirão Preto, SP, Brazil $-500 \mathrm{~nm}, 500 \mathrm{~mW} / \mathrm{cm}^{2}$ ) and polished with water abrasive papers (grit 400,600 and 1000). The thickness of each specimen was verified using a digital pachymeter (Digimess, São Paulo, SP, Brazil). After this, the specimens were randomly separated into 4 groups $(n=10)$ according to the surface protection: GI - no protection; GII - cyanoacrylate; GIII - Fortify Plus and GIV - Biscover.

The surface sealants were applied according to the manufacturers' instructions. After 37\% phosphoric acid etching for 15 seconds, a thin layer of each material was applied to specimens in the respective group, using a microbrush, followed by photoactivation (15 seconds for Biscover and 10 seconds for Fortify Plus). When cyanoacrylate was used, the product was applied followed by waiting 5 minutes for it to dry.

All specimens were carefully identified, stored in separate containers and kept in the dark until the initial color and opacity analysis were performed.

\section{Color analysis}

The color of the specimens was analyzed with a reflection spectrophotometer (Color Guide 45/0, BYK - Gardner GmbH, Geretsried, Germanyl using a white block (Standard optical geometry $45 \% 0^{\circ}$, Reflectance and Color Gardner Laboratory Inc. Bethesda, MA, USA). The color pattern was evaluated according to the CIE - L*, a* and b* color system described by Pires-de-Souza et al ${ }^{10}$ Initially, the color similarity among the different tested composites was analyzed using the initial color readings to compare the $L^{*}, a^{*}$ and $b^{*}$ coordinates of each resin with those of the control group, before submitting them to AAA. 
After the initial color analysis, the specimens were submitted to AAA IC-UV Adexim Comexim, São Paulo, SP, Brazil). This system uses light and steam to produce the aging of non-metallic materials. It is composed of a network of eight fluorescent light tubes of 40 watts with emission concentrated in the ultraviolet $\mathrm{B}$ region; with radiation concentrated at $280 / 32 \mathrm{~nm}$ and the exposure temperature is automatically controlled according to the programs established by the UV/condensation cycles. For aging the test specimens, the cycle of exposure to UV selected was 4 hours of exposure to UV-B at $50^{\circ} \mathrm{C}$ and 4 hours of water condensation at $50^{\circ} \mathrm{C}$ for a maximum period of 384 hours, which corresponds to 10 years of clinical use. ${ }^{23}$

After this period, the specimens were again submitted to color measurement, using the same method previously described. The color alteration $(\Delta E)$ of the samples was calculated according to the formula $\Delta E=\left[\left(\Delta \mathrm{L}^{*}\right)^{2}+\left(\Delta \mathrm{a}^{*}\right)^{2}+\left(\Delta \mathrm{b}^{*}\right)^{2}\right] 1 / 2 .^{10}$ Values of $\Delta \mathrm{E} \geq 3.3$ were considered clinically unacceptable. ${ }^{2}$

\section{Opacity analysis}

For this analysis, the specimens were submitted to the color readings on white and black patterns, considering only the $L^{*}$ coordinate, which was calculated according to the formula: Opacity $=L^{*} b /$ $L^{*} W$, where $L^{*} b$ corresponds to the reading of the $L^{*}$ coordinate against a black background and $L^{*} W$ against a white background. This procedure was performed before (initial opacity- 10) and after (final opacity - FO) AAA, and the difference in opacity between the two periods was calculated in percentage.

The color similarity values were submitted to statistical analysis using 1-way ANOVA and Tukey's test $(P<.05)$. Data concerning color stability was submitted to statistical analysis using 2-way ANOVA and Bonferroni's test $(\mathrm{P}<.05)$.

With the aim of comparing the surfaces of the test specimens before and after AAA, one test specimen from each group was submitted to surface evaluation by Scanning Electronic Microscopy (Jeol JSM 7500 - SII, Sony, Tokyo, Japan) at 1500X magnification. For this purpose, the samples were mounted on aluminum stubs and sputter coated with gold (300A to $500 \AA ̊)$ in a metallizer (Denton Vacuum, model Desk 11, Moorestown, NJ, USAl and their areas were analyzed by photomicrographs (15KV).

\section{RESULTS}

Color similarity

For the $L^{*}$ value, which represents the object brightness, it was observed that the composites TPH (67.2) and Charisma (68.5) were statistically similar between them ( $P>.05)$, differing from Concept (70.2) that showed statistically significant values $(\mathrm{P}<.05)$ in comparison with the other composites (Figure 1). For the $a^{*}$ coordinate (variation between green - red), it was verified that the TPH (6.4) showed the highest mean values, differing statistically from the other composites $(P<.05)$, which presented statistically similar values between them (Concept - 3.9 and Charisma - 4.1). For the b* coordinate (variation between blue - yellow), the highest mean values were found in Concept composite (16.6), differing statistically $(P<.05)$ from the other two tested materials, characterized by presenting a more yellowish color. The other composites presented similar performance between them (TPH 15.5 and Charisma - 14.7).

\section{Color stability}

Table 2 presents the mean values of $L^{*}$, $a *$ and $b^{*}$ coordinates before and after AAA. It was observed that for the control Group there was an increase in values of the $L^{*}$ coordinate for all the composites, indicating an increase in the luminosity of these materials. For the Biscover Group, the same coordinate behaved in the inverse manner, that is; there was a decrease in the values, indicating darkening of the samples. In the values for the $a^{*}$ coordinate, there was an increase for all the composites protected with Biscover, indicating a greater trend towards the color red. For the other groups, there was a reduction (control and Cyanoacrylate) or maintenance (Fortify Plus) of the values for the coordinate. The values for the $b^{*}$ coordinate increased in all the groups, indicating a trend towards becoming yellower, with the exception of the composites Concept and Charisma without surface protection.

After AAA, all the studied composites presented clinically unacceptable $(\Delta \mathrm{E} \geq 3.3)^{2}$ color alteration (Table 3). Irrespective of the composite, the highest $\Delta \mathrm{E}$ values were found when Biscover was used as surface sealant. Among the tested materials, the composite that presented the largest alteration in $\Delta \mathrm{E}$ was Concept $(\Delta \mathrm{E}=13.0)$.

When comparing the behavior of the composites with the control group, it was verified that all 


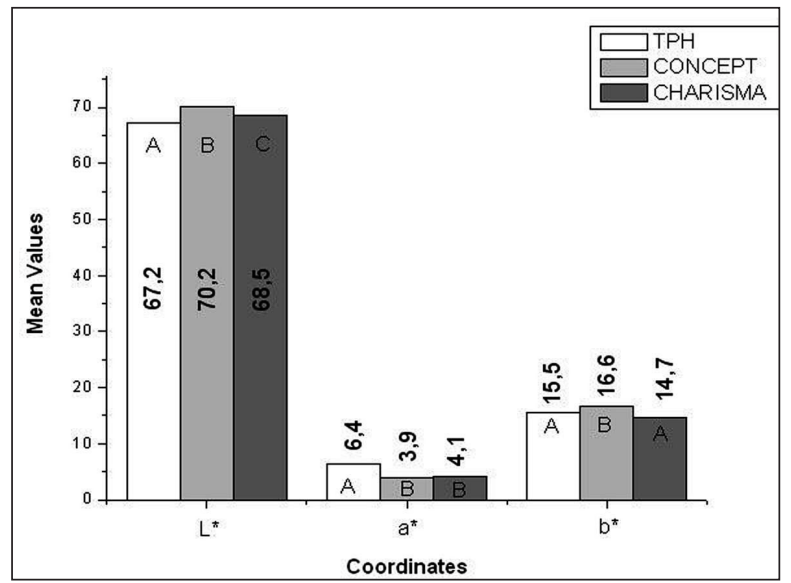

Figure 1. Mean values of $L^{*}, a^{*}, b^{*}$ before aging (1-way ANOVA - Tukey, $P<.05$ ). Different letters over bars mean statisticaly significant difference.

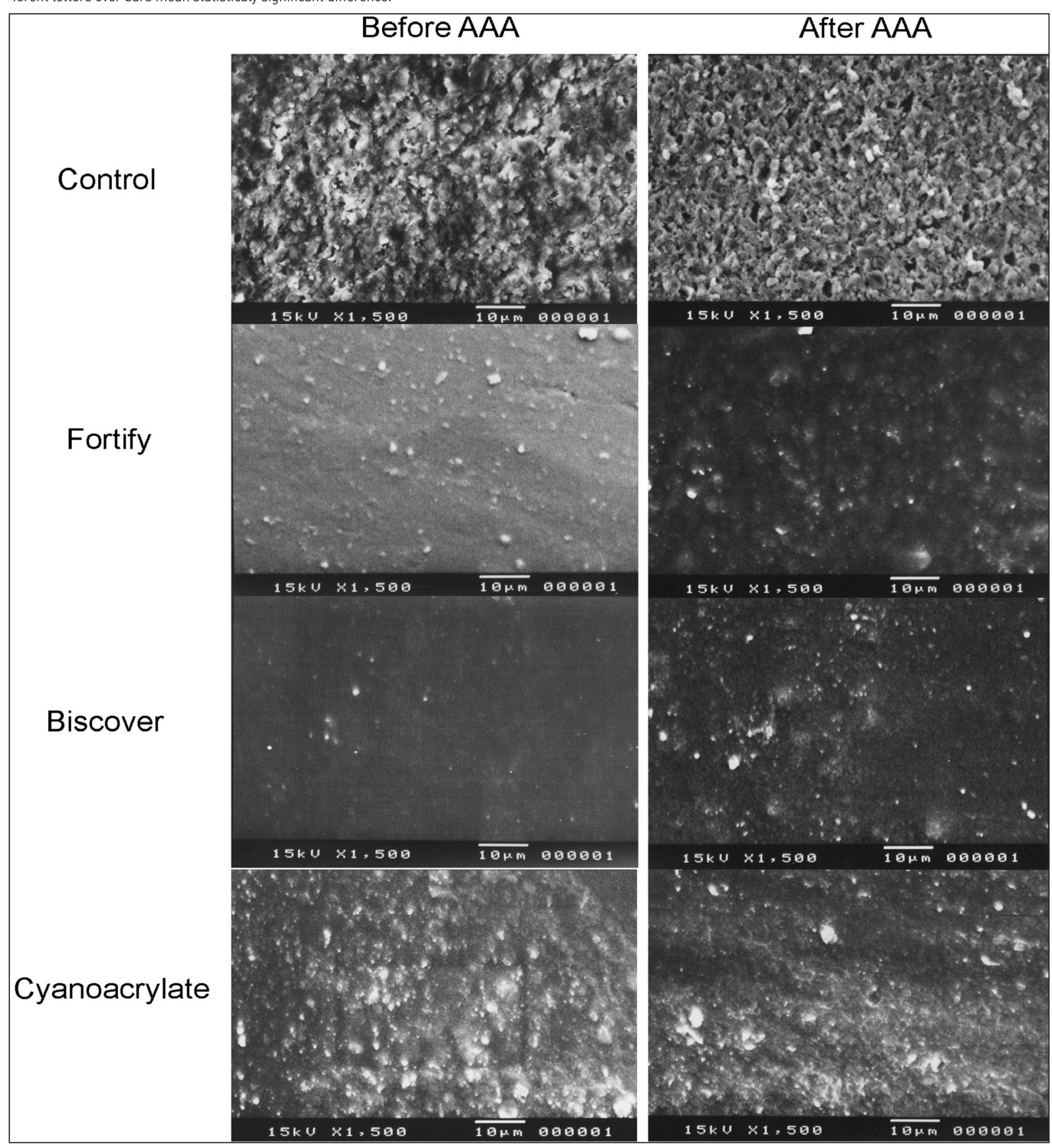

Figure 3. Photomicrographs of TPH before and after AAA.

January 2012 - Vol.6 
the protected groups presented mean values of $\Delta \mathrm{E}$ with statistically significant difference $(P>.05)$. For TPH composite, it was verified that the specimens with protected surfaces presented different values from those of the control group, with statistically significant difference ( $P>.05)$, except between Fortify Plus and Cyanocrylate $(P<.05)$. The smallest color alteration was verified for the control group (TPH $-\Delta \mathrm{E}=4.9$ ), in other words, in the materials without surface protection; and the largest color alteration was found in the composites sealed with the Biscover sealant (Concept $-\Delta E=13.0$ ). The color alteration in the composites sealed with For- tify Plus and Biscover was similar, presenting no statistically significant difference ( $P>05$ ).

\section{Composite opacity}

As shown in Figure 2, the control group presented the highest values for opacity when compared with the groups with surface sealants, irrespective of the composite. It could be observed that the TPH composite presented the lowest opacity alteration. Moreover, when using cyanoacrylate, the opacity remained the same after AAA for Charisma composite (0.04). The Fortify Plus sealant showed a very low percentage of alteration in opacity after

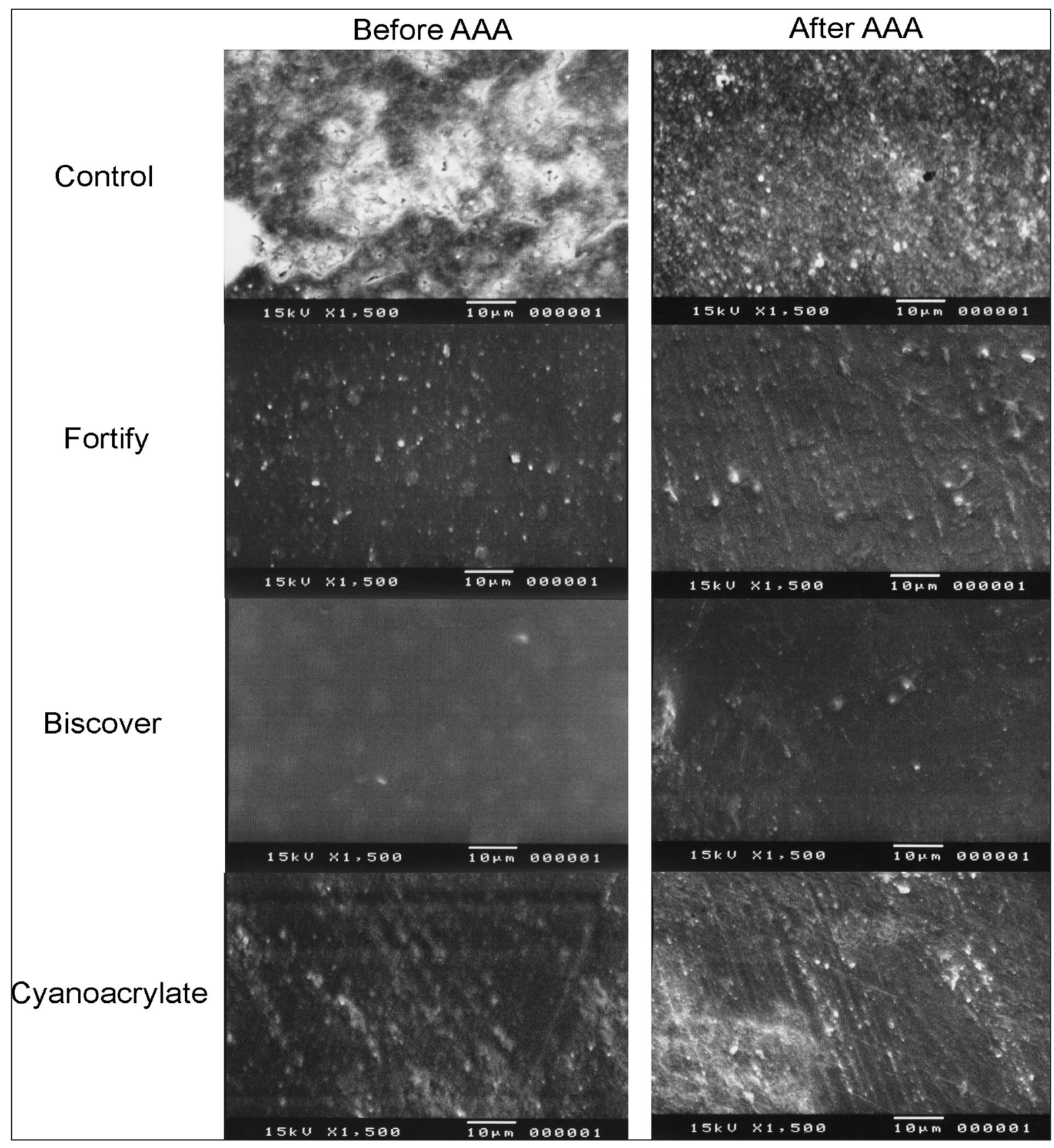

Figure 4. Photomicrographs of Concept before and after AAA. 
AAA for all the composites, the lowest alteration being for TPH (0.18) and Concept (0.25). Sequentially, the lowest alteration in opacity occurred in TPH protected with Biscover (0.47) and Charisma protected with Fortify Plus (0.66).

\section{Scanning Electronic Microscopy}

The photomicrographs (Figures. 3-5) demonstrated that for the composite TPH, before and after aging, the groups with surface sealants were shown to be very different when compared with the control group, showing greater surface regularity and being more regular for the Biscover Group
(GIV). When comparing the images in one and the same group, it was verified that AAA increased the surface irregularities of the specimens in all of the studied groups. For the other composite resins, a similar behavior was verified regarding the action of sealants and aging, except for the control Group, which, presented greater surface smoothness after AAA.

\section{DISCUSSION}

When dental materials are in use, they are submitted to rigorous clinical conditions, with alterations in $\mathrm{pH}$, salivary flow and temperature. In order

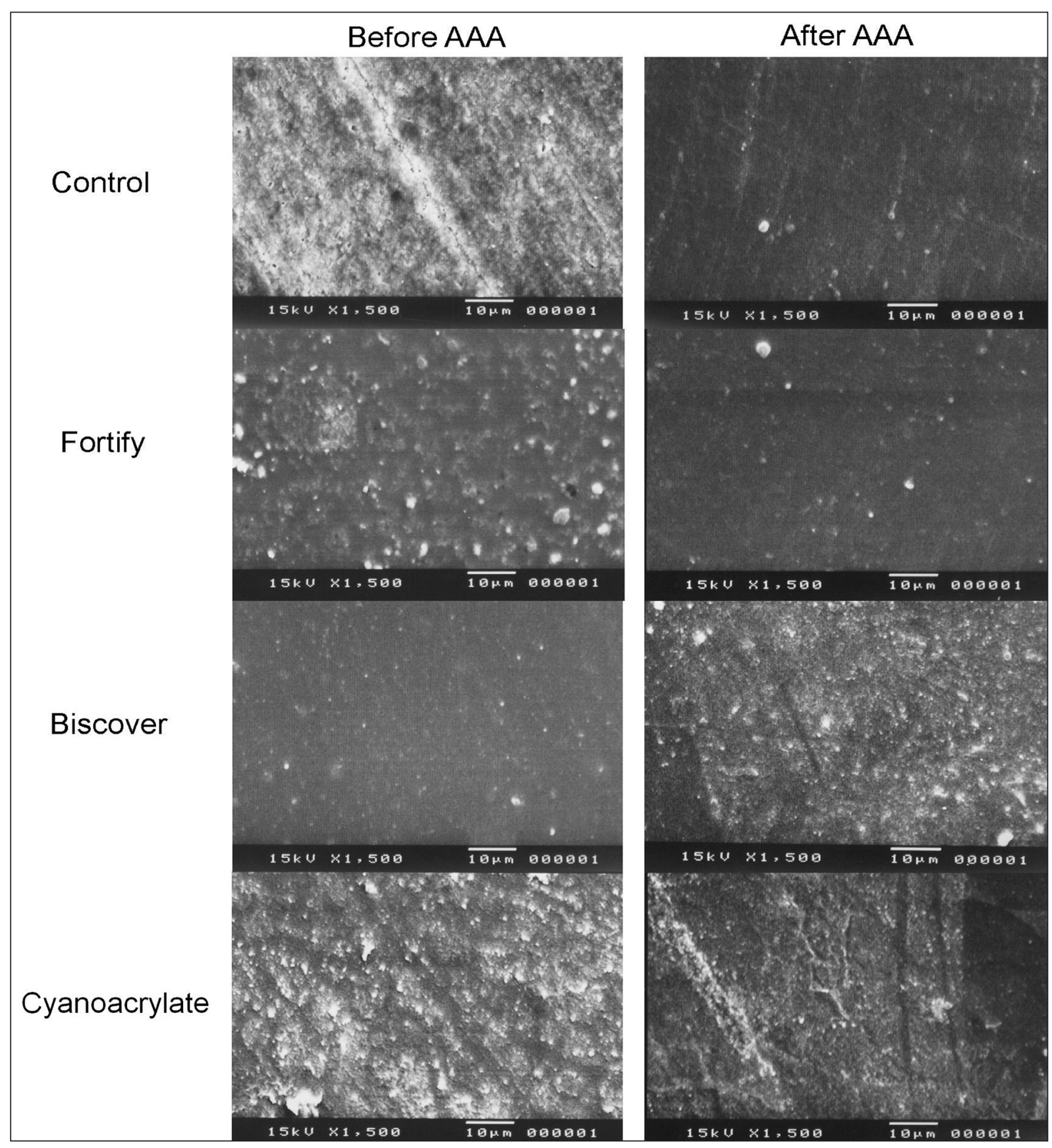

Figure 5. Photomicrographs of Charisma before and after AAA. 
to simulate the conditions to which resin composite restorations are exposed in the oral cavity, the literature shows that there are different methods to simulate their aging to verify the behavior of these materials in the long term. Among these, the methods of immersion in solutions such as water, teas, wine, coffee, mouth washes, among others are outstanding. ${ }^{24}$ There are also cycles of immersion in water at different temperatures alternated with light irradiation, ${ }^{25}$ and another method of artificial aging by exposure to light alternating with exposure to an environment with high humidity. 5,10 In the present study, this was the chosen method, in which the materials were submitted to the action of UV light and water condensation in 4-hour cycles for 384 hours. According to Zanin et al, ${ }^{26}$ color alteration of composite resins only occurs after 300 hours of the aging process.

Considering the results, the first null hypothesis of the present study was rejected because a lack of standardization by the manufacturers was noted, concerning the composite shades of different commercial brands. The $L^{*}$ coordinate was influenced by the shade designation for all resin composites $(\mathrm{P}<.05)$, a* coordinate was different only for TPH and $b^{*}$ for Concept. These results indicate that the differences in lightness by the brand were correlated with the shade designation. Thus, the dental professional may find some difficulty when choosing the material for clinical

Table 1. Tested materials.

\begin{tabular}{|c|c|c|c|c|}
\hline Material & Manufacturer & Mean particles size & Composition & Batch number \\
\hline TPH SPECTRUM & $\begin{array}{l}\text { DENTSPLY (Petrópolis, } \\
\text { RJ, Brazil) }\end{array}$ & $\begin{array}{l}0.8 \mu \mathrm{m}-77 \% \text { of } \\
\text { load by volume }\end{array}$ & $\begin{array}{l}\text { Bis-GMA, boron aluminum silicate and } \\
\text { silanized barium, pyrolytic silanized } \\
\text { silica, camphorquinone, EDAB, butylate } \\
\text { hydroxytoluene, dyes and minerals }\end{array}$ & 330568 \\
\hline CONCEPT ADVANCED & $\begin{array}{l}\text { VIGODENT (Rio de Janeiro, } \\
\text { RJ, Brazil) }\end{array}$ & $\begin{array}{l}0.4 \mu \mathrm{m}-67 \% \text { of } \\
\text { load by volume }\end{array}$ & $\begin{array}{c}\text { Bis-GMA, UDMA, ester of methacrylic } \\
\text { acid, barium silicate and aluminum } \\
\text { silicate }\end{array}$ & $003 / 06$ \\
\hline CHARISMA & $\begin{array}{c}\text { HERAEUS KULZER (Gruner Weg, } \\
\text { Hanal, Germany) }\end{array}$ & $\begin{array}{l}0.7 \mu \mathrm{m}-64 \% \text { of } \\
\text { load by volume }\end{array}$ & $\begin{array}{c}\text { Bis-GMA, TEGDMA, barium fluoride } \\
\text { glass, silica dioxide }\end{array}$ & 10204 \\
\hline BISCOVER & $\begin{array}{c}\text { BISCO Inc (Shamburg, } \\
\text { IL, USA) }\end{array}$ & & $\begin{array}{l}20-50 \% \text { Bis-EMA, } 20-40 \% \text { urethane ac- } \\
\text { rylate ester, } 20-40 \% \text { polyethylenoglycol }\end{array}$ & 400008665 \\
\hline FORTIFY PLUS & $\begin{array}{l}\text { BISCO Inc (Shamburg, } \\
\text { IL, USA) }\end{array}$ & $\begin{array}{l}0.4 \mu \mathrm{m}-17.3 \% \text { of } \\
\text { load by volume }\end{array}$ & $\begin{array}{c}\text { Amorphous Silica, Bis-EMA }(10-40 \%) \text {, } \\
\text { UDMA }(20-50 \%)\end{array}$ & 500009569 \\
\hline SUPERBONDER & $\begin{array}{l}\text { HENKEL Ltda. (Itapevi, } \\
\text { SP, Brazil) }\end{array}$ & & Cyanoacrylate ethyl ester & 711598 \\
\hline
\end{tabular}

Bis-GMA - Bisphenol A glycidyl methacrylate; EDAB - Etil 4-N,N-dimethyl amine benzoate; UDMA - Urethane dimethacrylate; TEGDMA - Triethyleneglycol dimethacrylate; Bis-EMA - Ethoxylated Bisphenol-A-Dimethacrylate.

Table 2. Mean values of $L^{*}, a^{*}$ and $b^{*}$ coordinates before and after AAA.

\begin{tabular}{|c|c|c|c|c|c|c|c|c|c|c|}
\hline & & \multicolumn{3}{|c|}{$\mathrm{TPH}$} & \multicolumn{3}{|c|}{ Concept } & \multicolumn{3}{|c|}{ Charisma } \\
\hline & & $\mathrm{L}^{*}$ & $a^{*}$ & $b^{*}$ & $L^{*}$ & $a^{*}$ & $b^{*}$ & $L^{*}$ & $a^{*}$ & $b^{*}$ \\
\hline \multirow{2}{*}{ Control } & Before & 67.1 & 6.4 & 15.4 & 70.1 & 3.8 & 16.6 & 68.5 & 4.1 & 14.7 \\
\hline & After & 69.0 & 4.8 & 18.2 & 76.2 & 2.4 & 8.5 & 72.8 & 3.0 & 8.8 \\
\hline \multirow{2}{*}{ Cyanoacrylate } & Before & 64.9 & 6.4 & 16.1 & 69.0 & 3.9 & 17.4 & 65.8 & 3.9 & 15.9 \\
\hline & After & 65.2 & 5.4 & 24.3 & 69.9 & 3.3 & 20.7 & 66.2 & 3.9 & 19.1 \\
\hline \multirow{2}{*}{ Fortify Plus } & Before & 64.7 & 6.6 & 17.0 & 68.0 & 3.7 & 17.0 & 65.5 & 4.2 & 15.7 \\
\hline & After & 64.2 & 6.0 & 25 & 66.9 & 3.7 & 24.9 & 64.9 & 4.1 & 21.9 \\
\hline \multirow{2}{*}{ Biscover } & Before & 64.4 & 5.9 & 17.8 & 68.2 & 2.9 & 17.4 & 65.4 & 3.5 & 16.5 \\
\hline & After & 62.2 & 7.1 & 28.9 & 65.5 & 4.9 & 29.9 & 62.8 & 5.5 & 27.5 \\
\hline
\end{tabular}

Table 3. Mean values (standard deviations) of Delta E (2-way ANOVA and Bonferroni's test, $\mathrm{P}<.05)$

\begin{tabular}{lcccc}
\hline & Control & Fortify Plus & Biscover & Cyanoacrylate \\
\hline TPH & $4.9(1.7) \mathrm{a}, \mathrm{A}$ & $8.0(0.8) \mathrm{b}, \mathrm{A}$ & 11.4 (0.9) c, A & $8.3(2.9) \mathrm{b}, \mathrm{A}$ \\
Concept & $10.2(2.0) \mathrm{a}, \mathrm{B}$ & $8.0(0.7) \mathrm{b}, \mathrm{A}$ & $13.0(0.8) \mathrm{c}, \mathrm{A}$ & $5.8(4.0) \mathrm{d}, \mathrm{B}$ \\
Charisma & $8.2(2.3) \mathrm{a}, \mathrm{B}$ & $7.9(0.7) \mathrm{a}, \mathrm{A}$ & $11.6(0.7) \mathrm{b}, \mathrm{A}$ & $3.3(1.5) \mathrm{c}, \mathrm{C}$ \\
\hline
\end{tabular}

Different letters (capital letters in the column and lower cases in the line) indicate results with statistically significant difference $(\mathrm{P}<.05)$. 
use, which would be important mainly in the case of repairing restorations. When compared with complete replacement of a restoration, repair presents advantages such as less wear of sound dental tissue, as well as lower cost, hence this has increasingly been the option of treatment over the last few years. ${ }^{27}$

Concerning the color alteration results, the hypothesis of the present study should also be rejected, since all composites showed values considered clinically unacceptable $(\Delta \mathrm{E} \geq 3.3){ }^{2}$ The highest $\Delta E$ values obtained for composites protected with Biscover can be explained by the "polished mirror" aspect, which this sealant gives the surface. ${ }^{24}$ As the method of color evaluation is based on the emission of a light beam that returns from the device, this "mirror effect" might have promoted a greater return of the luminous light. ${ }^{24}$ Furthermore, Biscover has $20-50 \%$ of Bis-EMA in its composition, which is the main component of the organic matrix and leads to this material being more susceptible to staining and degradation by AAA. ${ }^{24}$ The composites protected with Fortify Plus sealant also had high color alteration values $(\triangle E \geq$ 3.3). The explanation is the same as that presented for Biscover, since Fortify Plus also has higher amount of Bis-EMA (10-40\%) and UDMA (20-50\%) in its composition, thus likewise, it is susceptible to color alteration. ${ }^{24}$

Another factor that affects the performance of sealants is the thickness used over the composite. According to Lee et al, ${ }^{28}$ the thicker the layer of sealant applied on composite surface, the greater is the susceptibility to modify the composite color. In this study, only one layer of sealant was applied on the composites. However, due to the flowable characteristic and moistening ability of these materials, it was not possible to standardize the sealant thickness. The same limitation is found in the clinical situation.

The performance of cyanoacrylate was better when it was combined with Concept and Charisma composites. This protection provided smaller color alteration of such composites than the other surface protectors, however, the values continued to be clinically unacceptable $(\Delta E \geq 3.3){ }^{2}$

There are some factors that can influence composite opacity: ${ }^{29}$ 1) the inherent translucency of the materials components; 2) the load particles increase the light dispersion at the matrix/particle interface, which produces opaque materials if the refraction index of the composite components are different; and 3) the translucency of the composite depends on the size of the load particles. Composites with very small particles will produce superior translucency and better esthetic results. This would be the justification for the behavior of the composites studied in the present work.

When analyzing the initial opacity results of the composites (before AAA), it could be verified that in all groups, the highest opacity values were found for TPH, which presents load particles with a mean size of $0.8 \mu \mathrm{m}$ in a percentage of $77 \%$ by volume. Thus, there is less passage of light through the body of the composite, resulting in greater opacity. Concerning the other studied composites, although Charisma composite $(0.7 \mu \mathrm{m})$ presents a larger particle size than Concept $(0.4 \mu \mathrm{m})$, it was shown to have a smaller amount of load particles by volume (64\%), which justifies the lower opacity values. In this situation, a larger amount of light is able to pass through the material. ${ }^{8}$ After 384 hours of AAA, the performance of the composites as regards opacity remained unaltered. Nevertheless, it is interesting to notice that proportionally, Concept (the composite with smaller particles size) presented a higher alteration in opacity, probably because of the incompatibility of the refractive indexes between matrix and particles, as previously described. ${ }^{29}$

The use of surface sealants promoted a lower alteration in opacity in the composites after AAA, due to the lower surface degradation. ${ }^{11}$ Moreover, the sealants have a small amount of load particles in their composition, ${ }^{28}$ which contributed to the stability of composite opacity. Therefore, the hypothesis that composites protected by surface sealants would present less color alteration over time should be rejected. Moreover, it was expected that cyanoacrylate would present a performance similar to that of the surface sealants, and would therefore be a quick and low cost alternative for daily clinical practice.

AAA acted as a degrading factor on the surface of samples, which can be seen in the photomicrographs (Figures 3-5), in which one observes an increase in surface roughness in all the groups. In the control group of the composites Concept and Charisma, however, this occurrence was not verified, as these groups apparently presented an im- 
proved surface after AAA. This improvement could be justified by the greater water sorption that occurred during the aging process as a result of the smaller size of their load particles and the absence of protection, differently from that which occurred in the composite TPH. ${ }^{28}$

\section{CONCLUSION}

Based on the results obtained in this study, it may be concluded that:

1. Surface sealants were not effective in maintaining color stability of composites, but promoted lower opacity variation after AAA procedure, in comparison with the control group.

2. Concept and Charisma composites protected with Cyanoacrylate presented the lowest color alteration, although the results presented clinically unacceptable values.

\section{REFERENCES}

1. Vichi A, Ferrari M, Davidson CL. Color and opacity variations in three different resin-based composite products after water aging. Dent Mater 2004;20:530-534.

2. Ruyter IE, Nilner K, Moller B. Color stability of dental composite resin materials for crown and bridge veneers. Dent Mater 1987;3:246-251.

3. Powers JM, Bakus ER, Goldber AJ. In vitro color changes of posterior composites. Dent Mater 1988;4:151-154.

4. Uchida H, Vaidyanathan J, Viswanadhan T, Vaidyanathan TK. Color stability of dental composites as a function of shade. J Prosthet Dent 1998;79:372-327.

5. Schulze KO, Marshall SJ, Ganski SA, Marshall GW. Color stability and hardness in dental composites after accelerated aging. Dent Mater 2003;19:612-619.

6. Soares LE, Cesar IC, Santos CG, De Cardoso AL, Liporoni PC, Munin E, Martin AA. Influence of coffee on reflectance and chemistry of resin composite protected by surface sealant. Am J Dent 2007;20:299-304.

7. Santerre JP, Shajii L, Leung BW. Relation of dental composite formulations to their degradation and the release of hydrolyzed polymeric-resin-derived products. Crit Rev Oral Biol Med 2001;12:136-151.

8. Buchalla W, Attin T, Hilgers R, Hellwig E. The effect of water storage and light exposure on the color and translucency of a hybrid and a microfilled composite. J Prosthet Dent 2002;87:264-270.

9. Ferracane JL. Hygroscopic and hydrolytic effects in dental polymer networks. Dent Mater 2006;22:211-222.
10. Pires-de-Souza FCP, Garcia Lda F, Hamida HM, Assirati LC. Color stability of composites subjected to accelerated aging after curing using either a halogen or a light emitting diode source. Braz Dent J 2007;18:119-123.

11. Nie J, Linden LA, Rabek JF. A reappraisal of the photo polymerization kinetics of TEGDMA initiated by camphorquinone $\mathrm{N}, \mathrm{N}$ dimethyl $\mathrm{p}$ toluidine for dental purposes. Acta Polymer 1998;49:145-161.

12. Yap AUJ, Lee HK, Sabapathy R. Release of methacrylic acid from dental composites. Dent Mater 2000;16:172-179.

13. Imazato S, Tarumi H, Kobayashi K, Hiraguri H, Oda K, Tsuchitani Y. Relationship between the degree of conversion and internal discoloration of light-activated composite. Dent Mater 1995;14:23-30

14. Rueggeberg FA, Margeson DH. The effect of oxygen inhibition on an unfilled/filled composite system. J Dent Res 1990;69:1652-1658.

15. Douglas WH, Craig RG. Resistance to extrinsic stains by hydrophobic composite resin systems. J Dent Res 1982;61:4143.

16. Satou N, Khan AM, Matsumae I, Satou J, Shintani H. In vitro color change of composite - based resins. Dent Mater 1989;5:384-387.

17. Paravina RD, Kimura M, Powers JM. Color compatibility of resin composites of identical shade designation. Quintessence Int 2006;37:713-719.

18. Lee YK, Lim BS, Rhee SH, Yang HC, Powers JM. Color and translucency of A2 shade resin composites after curing, polishing and thermocycling. Oper Dent 2005;30:436-442.

19. Bertrand MF, Leforestier E, Muller M, Lupi-Pegurier ML, Bolla MJ. Effect of surface penetrating sealant on surface texture and microhardness of composite resins. Biomed Mater Res 2000;53:658-663.

20. Ramos RP, Chinelatti NA, Chinello DT, Dibb NG. Assessing microleakage in resin composite restorations rebounded with a surface sealant and three low - viscosity resin systems. Quintessensse Int 2002;33:450-456.

21. Tomlinson SK, Ghita OR, Hooper RM, Evans KE. Monomer conversion and hardness of novel dental cements based on ethyl cyanoacrylate. Dent Mater 2007;23:799-806.

22. Moretti-Neto RT, Mello I, Moretti ABS, Robazza CRC, Pereira AAC. In vivo qualitative analysis of the biocompatibility of different cyanoacrylate-based adhesives. Braz Oral Res 2008;22:43-47.

23. ASTM STANDARDS G154-00A. Standard practice for operating fluorescent light apparatus for UV exposure of nonmetallic materials. Annual Book of ASTM Standards. ASTM-Standards. Pennsylvania: United States, 2006: 646654. 
24. Lee YK, Powers JM. Combined effects of staining substances on resin composites before and after surface sealant application. J Mater Sci Mater Med 2007;18:685-691.

25. Sarafianou A, losifidou S, Papadopoulos T, Eliades G. Color stability and degree of cure of direct composite restoratives after accelerated aging. Oper Dent 2007;32:406-411.

26. Zanin FR, Garcia Lda F, Casemiro LA, Pires-de-Souza Fde C. Effect of artificial accelerated aging on color stability and surface roughness of indirect composites. Eur J Prosthodont Restor Dent 2008;16:10-14.

27. Hunter AR, Treasure ET, Hunter AJ. Increases in cavity volume associated with the removal of class 2 amalgam and composite restorations. Oper Dent 1995;20:2-6.

28. Lee YK, Lu H, Powers JM. Effect of surface sealant and staining on the fluorescence of resin composites. J Prosthet Dent 2005;93:260-266.

29. Kim SH, Lee YK, Lim BS, Rhee SH, Yang HC. Metameric effect between dental porcelain and porcelain repairing resin composite. Dent Mater 2007;23:374-379. 